\title{
Stress and Coping Strategies on Married Christian Students
}

\author{
YunitaSumakul ${ }^{1}$, Shanti N.Ch. Ruata ${ }^{2}$, Melissa M.F. Waturandang ${ }^{3}$, Aljuanika E. \\ Ering $^{4}$, Mariana L. Lausan ${ }^{5}$, Mercy W.K. Waney ${ }^{6}$ \\ IAKN Manado, North Sulawesi
}

\begin{abstract}
yunitasumakul@gmail.com,shantinataliach@gmail.com²,melissawaturandang@gmail.com³, aljuanikaering@gmail.com ${ }^{4}$, marianalausan@gmail.com ${ }^{5}$, mercywaney79@gmail.com 6
\end{abstract}

\begin{abstract}
Stress is usually happened in human life and each person responds to it in different ways. This study aimed to describe the factors causing stress, the physical and psychological conditions, and the coping strategies of married Christian students in overcoming the stress. This study applied descriptive qualitative approach. The participants of this study were the four students of Pastoral Counseling study program at Institut Agama Kristen Negeri Manado. Data were collected through observation and interview with the participants, friends, lecturers, and family. The result showed that: the factors causing stress were the double role, economic issues, interpersonal problems, and the lack of assertiveness; the physical and psychological conditions of each subject in stress were different, such as, headache, dizziness, stomach ulcer, insomnia, fever, concentration difficulty, and irritability; each subject used different coping strategies in overcoming stress. The coping strategies used for stress are accepting responsibility, problem solving, self-control, praying, and listening to religious songs.
\end{abstract}

Keyword: coping, stress, Christian married students

\section{Introduction}

Disruptive era can be interpreted as a period where changes happened so fast through innovations that alter the old system structure. This era is also associated with efficiency, speed, comfort, and quality. It brings a positive impact on human life. The rapid technological development facilitate humans to do things. However, there are also negative impacts, such as, the reduction in employment. Some works previously done by humans have been taken over by machines. The reduction in employment results in a higher level of competition. Humans are trying to improve competence in providing better careers, one of which is through education.

This disruptive era affects most aspects of human life such as personal, social, and learning aspects, especially for students preparing for careers. In personal aspect, students are required to improve their ability in using technology and they must be able to improve the soft skills (discipline, communication skills and good interpersonal skills, self-control, goal setting ability, and self-motivation). In social life, students must be able to use technology well, especially social media which can affect the interpersonal relationships with others. In learning aspect, students must be able to adapt by improving the ability to use learning media that is never used before and improving the insight and knowledge that can lead students to innovate. These requirements that must be achieved by students can cause stress, especially to the married students who is surely have a double role.

Getting married is what most people wish for. For some students, getting married young may not be a popular choice in modern times, but for other students, it is considered as a solution to the issue at hand. The reasons following student marriages include religious, 
economic, social and cultural reasons. Students' marriage has different problems from the general marriage. The problem is about the roles division. Married students will deal with household tasks according to the role as a husband or a wife. Nevertheless, they also have to carry out the role as a student that is attending lectures, doing assignments, sitting an exam, etc [1].

Performing different roles as a student and a housewife is not easy and it triggers stress. Stress is normal part of each individual's life. We can feel physical stress when we have too much work and when we are not getting proper sleep or we are not able to eat properly and when we are becoming ill. Stress is causing most people in similar way. Acute stress leads to quick changes all through the body. Stress is generally defined as the body's common response or reaction to demands made on it, or to disturbing events in the environment. It is a process by which we perceive and cope with environmental threats and challenges. Personal and environmental events that cause stress are known as stressors [2].

There are some definitions about stress. Sutherland and Cooper defined stress which is a physical or psychological stimulus which, when impinging upon an individual produces strain or disequilibrium [3]. Stress is generally due to conflict emanating from high aspirations and goal attainment. Stress may also result from indecisiveness and / or failure to cope with the demanding situation. Stress is common for all, but the degree varies which depends on various intra-psychic and interpersonal factors. Stress prone people experience more health related problems and experience difficulties in interpersonal areas. Although stress cannot be totally eliminated from the individual's life it can be minimized which may help in leading a healthy and prosperous social life. It is thus quite important to discuss about some effective coping strategies to manage the human stress [4]. Colbert said that stress is the pressures of life and how one perceives, believes, reacts, and copes with these pressures [5].

According to Georgia and Lanoil, women have certain stress that is different from men. In addition, the roles of man and woman are also distinguished by the culture which makes women experience stress that is not experienced by men. According to Vashdev, brain structure causes women experiencing more stress than men. A woman's brain is smaller than a man's but it works 7-8 times harder than a man's brain when dealing a problem. Moreover, there is a bridge between the right brain and the left brain, it is called corpus callosum. The bridge in men's brain is thinner and rare, whereas in women's, it is thicker and $30 \%$ more. This thicker bridge allows women viewing a problem wider and connecting one thing to another. It creates a more complex problem [6]. In health psychology, there are three approaches to explain stress.

a) Stress as a stimulus. This approach describes stress as an environmental stimulus we face in the form of disturbing and burdening situations. The situation in question is threatening demands, such as storms, earthquakes, landslides, epidemics, family death, or divorce. All of them are unpleasant experiences and may result in tension

b) Stress as a response. This approach considers stress as a physical and psychological reactions to the stressors. Some experts define stress as "a non-specific response from the body to every demand". When someone is dealt with a situation that can lead to stress, stress response is occurred. There are chemical reactions in the body, increasing hormones flowing into the blood, intense emotions, and increasing tension. Concerning with this state of stress, a concept is then formulated to describe stress. It is called General Adaptation Syndrome (GAS) which is an automatic response on any physical or emotional threat to the well-being/state of an organism

c) Stress as an interaction between individuals and the environment. From daily life, it can be seen that a matter can cause stress to someone but not to others [7]. 
In Christian perspective, stress is a condition of human personality due to the sinful nature of human. Sinful in the sense of status, means that human is separated from God, the creator. Romans 3:23 states that "for all have sinned and come short of the glory of God". Losing glory makes human separated with God. It results in uneasy, uncomfortable, insecure, uncertain, hopeless, afraid, and anxious feelings which lead human to stress.

\subsection{Stress Triggers}

Stress triggers can be a situation or condition, for example a parent's death, divorce, argument with superiors, economic pressure and so on. It is needed to remember that in living everyday life, subjective appreciation will be happened to each individual. The subjective appreciation consists of two main elements, as follows:

\section{a) Primary assessment}

This approach describes stress as a stimulus, videlicet the individual evaluate the meaning of an event/condition for himself, and whether the event/condition is connected to his wellbeing. If it is connected, then the next question is whether it is a disadvantageous challenge/threat, or it is something safe and even has positive impact. If the situation is perceived as threatening and negative, then the individual will sense an insistence to deal with the problem. Afterwards, there will be secondary assessment process.

\section{b) Secondary assessment}

This approach focuses on individual ability to deal with the stress sources where individual ask how to face and overcome the demand. At this stage, the individual will also evaluate the ability and skills within himself and the environment support to tackle the demands or the issues at hand [7].

All forms of stress, however, produce a very well-documented physical reaction in the body. There is another system of classification that may give us a more detailed picture of stress-causing agents. These one places stress into four general categories:

a) Physical stress, often arises from a lack of sleep, overworking, excessive exercise, physical injury or trauma such as a motor vehicle accident, surgeries, infections, physical disease, and chronic pain

b) Emotional and mental stress, is also called psychological stress, and we will use the terms emotional, mental, and psychological stress interchangeably since there is a great deal of overlap in medical research when it comes to these terms. The worries and general anxiety that often arises from too much work and too little play, too much debt, marital difficulties, children using drugs or alcohol, and other mental stresses related to one's work, finances, family issues, or school

c) Chemical stress, comes from excessive of various substances such as excessive sugar, caffeine, stimulants, alcohol , nicotine, and food additives

d) Thermal stress, related to being exposed to extremes in temperature, either hot or cold, for prolonged periods of time [5].

\subsection{Stress Stages}


Hans Selye said that there are three stages of stress.

a) The alarm reaction

The alarm reaction, riggers a fight or flight response. When sudden stress is experienced, the alarm reaction occurs when a person perceives he is being attacked or is in a dangerous situation, not only when a person is actually in such a bright circumstance. The alarm reaction generally produces a short-term burst of adrenaline, which creates a temporary "high" and produces energy.

\section{b) The resistance stage}

The resistance stage, a person at this level is seeking to adapt to an ongoing negative situation. In this stage, the body no longer reacts with a fight or flight response, but rather a coping response. The body continues to produce a large amount of stress hormones, especially cortisol. It is also the stress hormone secreted when a person just thinks or rehashes a stressful event in such a way that the endocrine system stays revved up. When the body is under prolonged stress, cortisol remains elevated. At times, cortisol levels can remain elevated throughout the day and, for many people, well into the night. This often leads to insomnia and sleep disturbances. The brain eventually loses its sensitivity to cortisol and is unable to regulate cortisol production.

\section{c) The exhaustion stage}

The exhaustion stage, the body actually begins to break down, and the risk of chronic disease increases dramatically. The exhaustion stage is technically referred to as adrenal exhaustion. Adrenal exhaustion usually leads to being burned out mentally, physically, and emotionally. As the adrenal function is impaired, every organ and system in the body is affected. Those who experience adrenal exhaustion often feel very tired. People in the exhaustion stage are very prone to developing autoimmune diseases [5].

\subsection{Stress and Health}

Selye attributes the stress response on the activation of the anterior pituitary adrenal cortex system. He concludes that stressors affect neural circuits in stimulating the release of adrenocorticotropic hormone $(\mathrm{ACTH})$ from the anterior pituitary, and ACTH in turn will trigger the glucocorticoid release from the adrenal cortex, so that glucocorticoid produce many effects of the stress response. Circulating glucocorticoids level is the physiological measurement of stress commonly applied. Stressors also activate the sympathetic nervous system and as a result it increases the amount of epinephrine and norepinephrine released from the adrenal medulla. Most modern stress theories acknowledge the important roles of the two systems [8].

An entire system of physical responses involves primarily the hormones epinephrine and norepinephrine. These two hormones have a dramatic effect on the sympathetic nervous system during periods of intense stress. When a stressful event occurs, the brain perceives the stress and response by triggering the release of specific hormones from the hypothalamus, pituitary gland, and adrenal gland. The stress response also triggers the adrenal glands to release epinephrine, which is also called adrenaline. The sympathetic nerves are stimulated to release more epinephrine throughout the body. the sympathetic nerves are located throughout 
the body, even in our organs and tissues, so when they are stimulated, your heart rate increases, your colon is stimulated, you sweat, your bronchial tubes dilate allowing more oxygen to enter, and so on.

Adrenaline is a powerful hormone that has far reaching physical effects. It focuses on the brain, sharp eyesight, and contracts muscles in preparation of fight or flight. It also causes blood pressure and heart rate to increase, even as blood vessels constrict. When adrenaline begins to flow through the body, digestion shuts down as blood is shunted away from the digestive tract and sent to the muscles.

In normal conditions, this cycle of adrenaline / cortisol and fatigue / rest in response to short-term stress is generally harmless to the body. But long-term stress, however, can keep the stress hormones pumping into a person's system on a nearly constant basis. For example, if a person is living for years in a state of unresolved anger toward a spouse or child, the flow of adrenaline can become excessive. Prolonged, elevated levels of adrenaline may increase heart rate and blood pressure to the point that a rapid heartbeat and high blood pressure become the norm [9].

Stress will precipitate physical, psychological, and behavioral impacts. According to Akoso, the physical symptoms are hair loss, skin problems, respiratory disorder, digestive disorder, nervous system disorder, cardiovascular disease, muscle disorder, mouth disorder, and reproductive system disorder. On the other hand, the psychological symptoms are irritability, insomnia, apathy, moodiness, difficulty concentrating, impulsive behavior, crying spells, nightmares, hyperactivity, anxiety, compulsive behavior and addiction [10].

Nevertheless, stress does not always have a negative impact. In certain cases, stress becomes invaluable. Stress makes us aware and it increases the ability to respond as well as to fight back and the ability to use all the personal resources to achieve goals. Stress that has positive impact is known as eustress. In contrast, stress associated with negative emotions is called distress [7].

\subsection{Coping Strategies}

Everyone has their own way in overcoming stress. It is called coping stress. Lazarus and Folkman define coping strategies as changes from one condition to another as a way to face unexpected situations [1]. Coping is defined as realistic and flexible thoughts and actions that solve problems and thus reduce stress. The psychoanalytic ego psychology approach differentiates among numbers of processes that people use to handle person-environment relationships. Menninger, in one of the earliest formulations, identifies five orders of regulatory devices that are ranked according to the level of internal disorganization they indicate. At the top of this hierarchy are strategies for reducing tensions caused by stressful epidoses in the course of ordinary living. These strategies are called copung devices, and include self-control, humor, crying, swearing, weeping, boasting, talking it out, thinking through, and working off energy [11].

Lazarus and Folkman divide coping strategies for stress into two categories:

a) Problem-Focused Coping (PFC) is a response attempting to modify the stress source by facing the real situation. This coping is used to reduce the stressors or to tackle stress by learning new ways or skills. The coping strategies oriented to the Problem-Focused Coping (PFC) consist of problem solving, confrontational coping, and seeking emotional support

b) Emotion-Focused Coping (EFC) is an effort to seek and obtain a sense of comfort and reduce the pressure caused by stress, this coping is used to manage emotional responses 
to stress. If the individual is unable to change the stressful conditions, then he will tend to manage his emotions. The coping strategies oriented to Emotion-Focused Coping (EFC) are distancing, self-control, and accepting responsibility.

\section{Study Methods}

\subsection{Research Approach}

This study was qualitative using a descriptive case study technique. Qualitative research focuses on the phenomenon of occurring in natural settings, and the data are analyzed without using statistics. Qualitative research always takes place on the field or wherever the participants normally conduct their activities. It is often referred to as field research. Qualitative research entails observation and / or unstructured interviewing in natural settings. The data are collected in a spontaneous and open-ended style [12].

This study is entitled Stress and Coping Strategies on Married Christian Students. It describes the factors causing stress, the physical and psychological conditions, and the coping strategies for stress used by married Christian students.

\subsection{Subjects of the study}

The subject of this study was the college students studying at department of Pastoral Counseling in Institut Agama Kristen Manado. The number of participants were 4 students.

Table 1. Research Subject

\begin{tabular}{lccc}
\hline \multicolumn{4}{c}{ Table 1. Research Subject } \\
\hline I. & Initial & $\begin{array}{c}\text { Ag } \\
\text { e }\end{array}$ & Grade \\
\hline 2. & RN & 19 & 3 \\
3. & PK & 21 & 5 \\
4. & PM & 20 & 5 \\
\hline
\end{tabular}

\subsection{Data Collection Technique}

The data collection procedure in qualitative research involves four basic types with their strengths and limitations, namely observation, interview, documents, audio and visual materials [13]. In this study, the technique of collecting data used by the writer is observations, and interviews.

a) Observation is involved whenever a recorder, human or mechanical, observes events for the purpose of collecting information and making a permanent record of them. This is a broad definition since observation is a versatile data collection method. Observation has been used as the data collection method both in highly structured forms of research and in flexible method studies in participant observation form [14]. The writers used repeated observation method where he was repeatedly observing students behavior specifically on the field. The writers tried to answer the problems through observing the students studying at Pastoral Counseling. The writers used participant observation where they 
were actively involved in observing activities. They used observation guidelines in checklist and field notes forms. Observations made by the writers are to directly and naturally observe all activities in teaching and learning process.

b) Interviews; in this study writers used interviews as one of the data collection techniques where the writers and participants asking and answering questions to achieve certain goals [15].

\subsection{Data Analysis}

According to Miles and Huberman, qualitative data analysis consists of three components that constitute concurrent flows of activity: data reduction, data display, and conclusion drawing and verification. (1) Data reduction refers to the process of selecting, focusing, simplifying, abstracting, and transforming the data that appears in field notes or transcriptions. Activities such as writing summaries, coding and clustering chunks of data or identifying themes may be carried out in order to reducing data; (2) Data display, the second major analysis activity, involves the organized and condensed assembly of information that permits conclusion drawing. Particularly, when qualitative data are displayed as extended text that is poorly structured and bulky, the goal is to find better forms of data displays such as matrices, graphs, charts and networks that make information more immediately accessible; (3) The third concurrent stream of activity is conclusion drawing and verification. Here, the writers note regularities, patterns, explanations, possible configurations and propositions. At the same time, this conclusion has to be tested continuously for their plausibility and confirmability as the analysis proceeds [14].

In this study, the writers used data analysis with the following stages: (1) Data reduction. After the writers collecting data from observations, interviews, and documentation, they simplified the data. It was done to get more data focused on the research problem to find a clear and precise picture; (2) Data display. From the data reduction result, the writers presented the data in a better form; (3) Drawing conclusion and verification was to get final results of the research conducted and to present it.

\section{Result and Discussion}

Stress is commonly experienced by everyone. Stress can bring positive impact in performing roles as a student and a housewife. However, excessive stress can also have negative impact in performing these roles. The impacts do not depend on the event or situation experienced but on the individual's perception of it. Individual perceptions vary when dealing with problems or threats in the same situation and condition.

According to the research result, the factor causing stress to the participants in this case the married students was the double role (as a student and a housewife). Consequently, they felt tired and some tasks left undone. Economic and interpersonal problems also contributed in causing stress. Furthermore, stress on the participants was also caused by unassertive behavior in conveying feelings or asking for help to the other family members in finishing the tasks.

The participants must have performed their responsibilities as students, namely being present on time in class, submitting assignments on time, and increasing competence. Moreover, they also had to carry out responsibilities as a wife and a 
mother, especially for CK and RN who live in the in-law's house. Some of the tasks that must be done were cleaning the house before leaving for campus and preparing the needs of husband and children. The participants assumed that all of those were responsibilities that needed to be done as the housewives although they felt it is too much and they were unassertive to ask for help from other family members. These things made them depressed and stress.

Economic problems were also experienced by all participants. The husband works to fulfill the needs of the family and to pay the tuition fee of the wife which sometimes has an impact

The stress experienced could cause different symptoms to each participant. The main symptoms were headache and stomach ulcer. The other physical symptoms included dizziness, insomnia, and fever. On the other hand, the psychological symptoms were concentration difficulty and irritability.

When experiencing something threatening and causing stress, individuals will use coping strategies to overcome it. According to the research result, the strategies used by the participants were different in dealing with the stress experienced. The strategies used were accepting responsibility, problem solving, self-control, praying, and listening to spiritual songs. CK dealt with stress by self-control and continuing performing her responsibilities as a student and a housewife. In contrast, PK overcame stress by finding solutions that is dividing tasks with family members so that she can concentrate and do her responsibility as a student without ignoring her duty as a housewife. $\mathrm{RN}$ overcame stress by avoiding the stress sources and trying to control her emotions. PM dealt with stress by praying and listening to religious songs.

\section{Conclusion}

Married students experienced stress because of performing double role, they must carry out the responsibilities as a student and as a housewife. Based on the research on the four married Christian students, it can be concluded that (1) the factors causing stress are the double roles, economic problems, interpersonal issues, and lack of assertiveness; (2) the psychological and physical conditions of each subject are different when experiencing stress such as headache, dizziness, stomach ulcer, insomnia, fever, concentration difficulty , and irritability ; (3) each subject used different coping strategies in dealing with stress. The coping strategies for stress used are accepting responsibility, problem solving, self-control, prayer, and listening to religious songs.

The results of this study can be useful for both individuals and educational institutions in relation to stress management especially for the married students.

\section{Acknowledgment}

We thank all those who have helped in the research process. We hope this research can be a reference for the development of psychology and for educational institutions in providing guidance to students, especially those who perform double role. 


\section{References}

[1] Rositoh, F., Sarjuningsih, Sa'adati, T.I.:Strategi coping stress mahasiswa yang telahmenikahdalammenulistugasakhir. Vol. 1, No. 2, pp.59-74, Happiness, journal od Psychology and Islamic Science (2017).

[2] Mathew, C.P.: Stress and Coping Strategies among College Students. Vol. 22, No. 8, Ver. IV, pp. 40-44, IOSR Journal of Humanities and Social Science (2017).

[3] Sutherland, V.J., Cooper, C.L. Strategic Stress Management, Palgrave, New York, pp. 61, (2003)

[4] Mahakud, G., Sharma, V., Gangai, K.N.: Stress Management (Concept and Approaches). Vol. 1, No. 6 Researchgate(2013)

[5] Colbert, D.: Stress Less. Siloam, New York, pp. 7-16, 19-26(2008).

[6] Vashdev, G.: Happiness Inside. Jakarta: PT. MizanPublika, pp.59-60 (2012).

[7] Soewondo,S., Menaldi, A., Hanum, L.:Stres, ManajemenStres, danRelaksasiProgresif. LPSP3 Universitas Indonesia, Jakarta, pp. 3-7, 10 (2017).

[8] Pinel, J.P.J.:Biopsikologi. Ed. 9.PustakaPelajar, Yogyakarta. pp. 557-558 (2012)

[9] Colbert, D.:Deadly Emotions. Thomas Nelson Inc, Nashville. pp. 13-16 (2006)

[10] Akoso, B.T.Akoso, G.H.E,:BebasStres, Yogyakarta: Kanisius, pp. 5-6 (2013).

[11] Lazarus, R.S, Folkman, S.: Stress, appraisal, and coping. Springer Publishing Company, New York. pp. 118-119 (1984)

[12] Jackson. SL.: Research methods, Thomson Wadsworth, USA. pp.88 (2008)

[13] Raco, JR.:Metodepenelitiankualitatif. Jakarta: PT. Grasindo.pp.49-50 (2010).

[14] Daniel, A.: Perception gaps between headquarters and subsidiary managers. Gabler: Germany. pp.138 (2009).

[15] RK. Yin. Studikasus: desaindanmetode. PT RajaGrafindoPersada, Jakarta. pp.13 (2012). 